\title{
SEM characterization of gelatin-ionic liquid functional polymers
}

\author{
R.N.L. Carvalho*, S.C. Matias*, N.M.T. Lourenço* and L.P. Fonseca**** \\ *IBB, Institute for Biotechnology and Bioengineering, Centre for Biological and Chemical Engineering, \\ Instituto Superior Técnico, Av. Rovisco Pais, 1049-001 Lisboa, Portugal \\ **Department of Bioengineering, Instituto Superior Técnico, Universidade Técnica de Lisboa, Av. Rovisco Pais, \\ 1049-001 Lisboa, Portugal
}

ION JELLY ${ }^{\circledR}$ patented technology is based on the cross-linking of Ionic Liquids (ILs) with Gelatin that results in a viscous gel that can be molded into a film or a block, and solidifies by cooling below $35^{\circ} \mathrm{C}$ [1]. The outcome of this combination is a transparent, light and flexible conductive polymer that adapts perfectly to a great variety of surfaces. Some of the key properties of ION JELLY ${ }^{\circledR}$ are: high stability up to $180^{\circ} \mathrm{C}$, large electrochemical window and bio-compatibility $[2,3]$. Taking in consideration the attractive attributes of ILs, that provide a stable and friendly environment for the enzymes, where they retain their catalytic activity, combined with the morphologic advantage of gelatin, we have decided to study this new protein-ionic-based material regarding water content, swelling behaviour, and structural morphology by scanning electron microscopy (SEM).

The properties of $[\mathrm{emim}]\left[\mathrm{EtSO}_{4}\right]$ and $[\mathrm{bmim}]\left[\mathrm{N}(\mathrm{CN})_{2}\right]$ ION JELLY ${ }^{\circledR}$ films were compared with those of solely gelatin. Thin films were prepared with different amounts of water or phosphate buffer and left to maturate in a controlled atmosphere for 4 days. Swelling was carried out in water at $4^{\circ} \mathrm{C}$ and films were lyophilized afterwards. SEM images of ION JELLY ${ }^{\circledR}$ and gelatin films were obtained prior and after these steps.

ION JELLY ${ }^{\circledR}$ films were rubbery while gelatin films were glassy. Water-made ION JELLY ${ }^{\circledR}$ had completely smooth surfaces, just like gelatin, but buffer-made ION JELLY ${ }^{\circledR}$ exhibited salt crystals on the surface, as well as some superficial pores (Figure 1). Free water content in $[\mathrm{emim}]\left[\mathrm{EtSO}_{4}\right] \mathrm{ION} \mathrm{JELLY}^{\circledR}$ was found to be greater than $[\mathrm{bmim}]\left[\mathrm{N}(\mathrm{CN})_{2}\right]$ ION JELLY ${ }^{\circledR}$ and gelatin.

The swelling ratio of both types of ION JELLY ${ }^{\circledR}$ was close to $100 \%$, while gelatin swelled 8 times more. The swollen lyophilized gelatin films formed a heterogeneous and highly porous network (Figure 2), while ION JELLY $^{\circledR}$ films were more homogeneous with a lower degree of porosity (Figure 3).

These results showed that ION JELLY ${ }^{\circledR}$ is a polymer with a more tightly bound structure than gelatin. This material allows water to penetrate, but possesses a higher rigidity that prevents too much mobility of the polymeric chains. Considering that it's a biocompatible polymer, lyophilized swollen ION JELLY ${ }^{\circledR}$ could have potential applications as a scaffold for biological material.

\section{References}

1. Vidinha P. et al., Chem. Comm., 5842-5844, 2008.

2. Cordas C.M. et al., N. Biotechnol., 25:S138-S139, 2009.

3. Lourenço N.M.T. et al., React. Funct. Polym., 71:489-495, 2011.

Financial support received from the Portuguese Science and Technology foundation (Fundação para a Ciência e Tecnologia) under the grants SFRH/BD/77568/2011, PTDC/EBB-BIO/114288/2009, PTDC/EBBBI/099237/2008 and SFRH/BPD/41175/2007 and Projecto Estratégico IBB: PEst - OE/EQB/LA0023/2011 


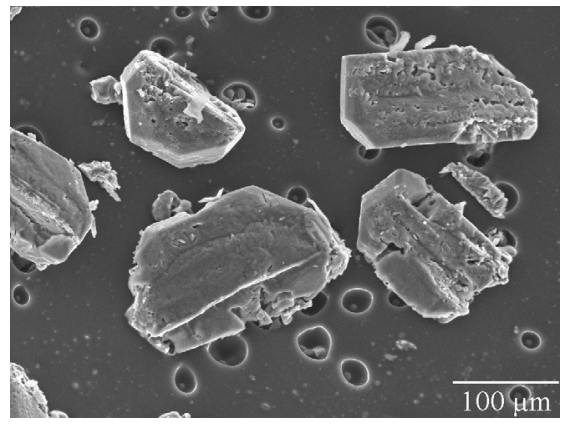

Figure 1. SEM image of $[\mathrm{bmim}]\left[\mathrm{N}(\mathrm{CN})_{2}\right]$ ION JELLY ${ }^{\circledR}$ made with sodium phosphate buffer exhibiting salt crystals.
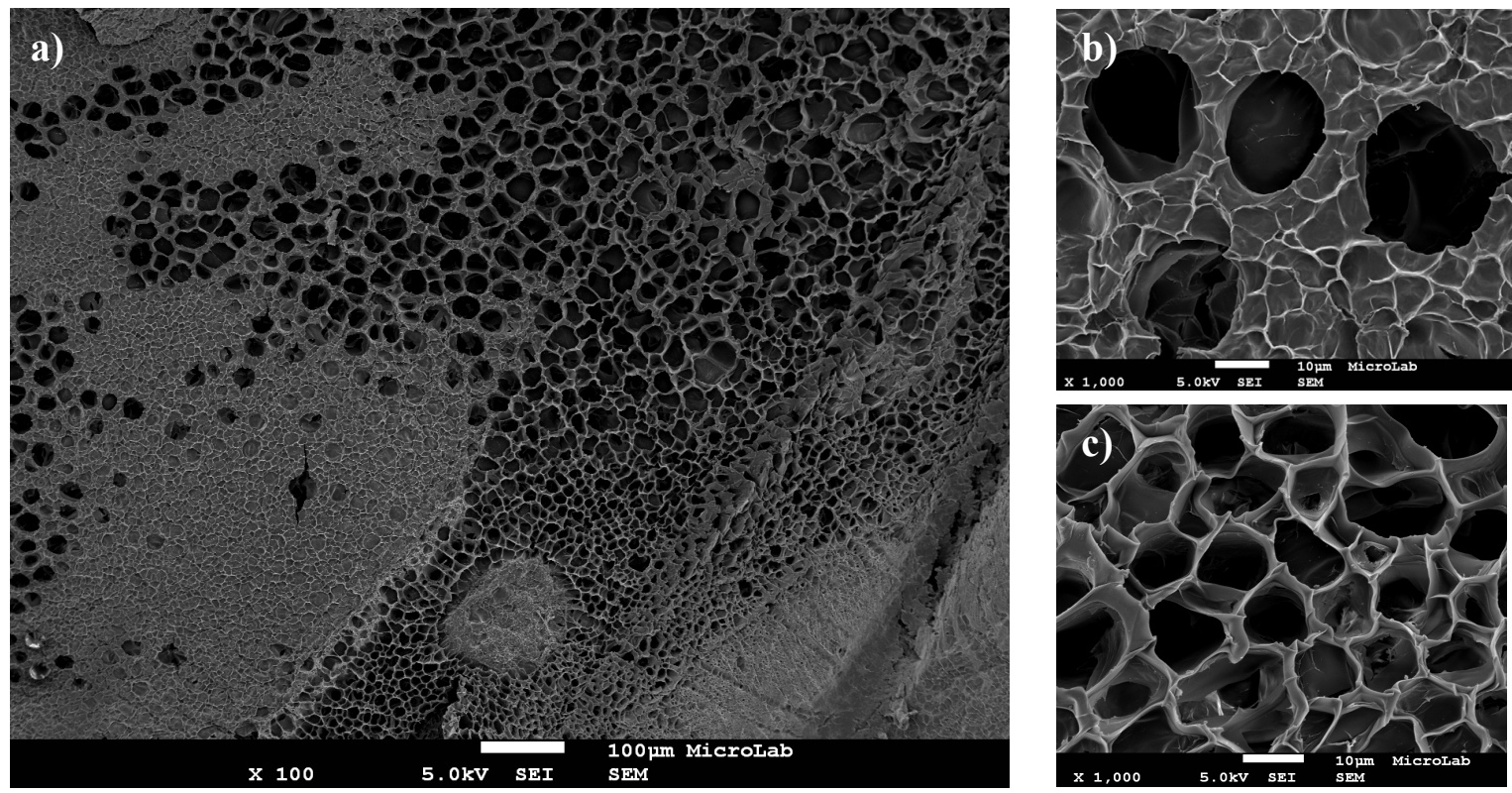

Figure 2. SEM images of lyophilized swollen gelatin films. a) General view; b) and c) Magnified views.
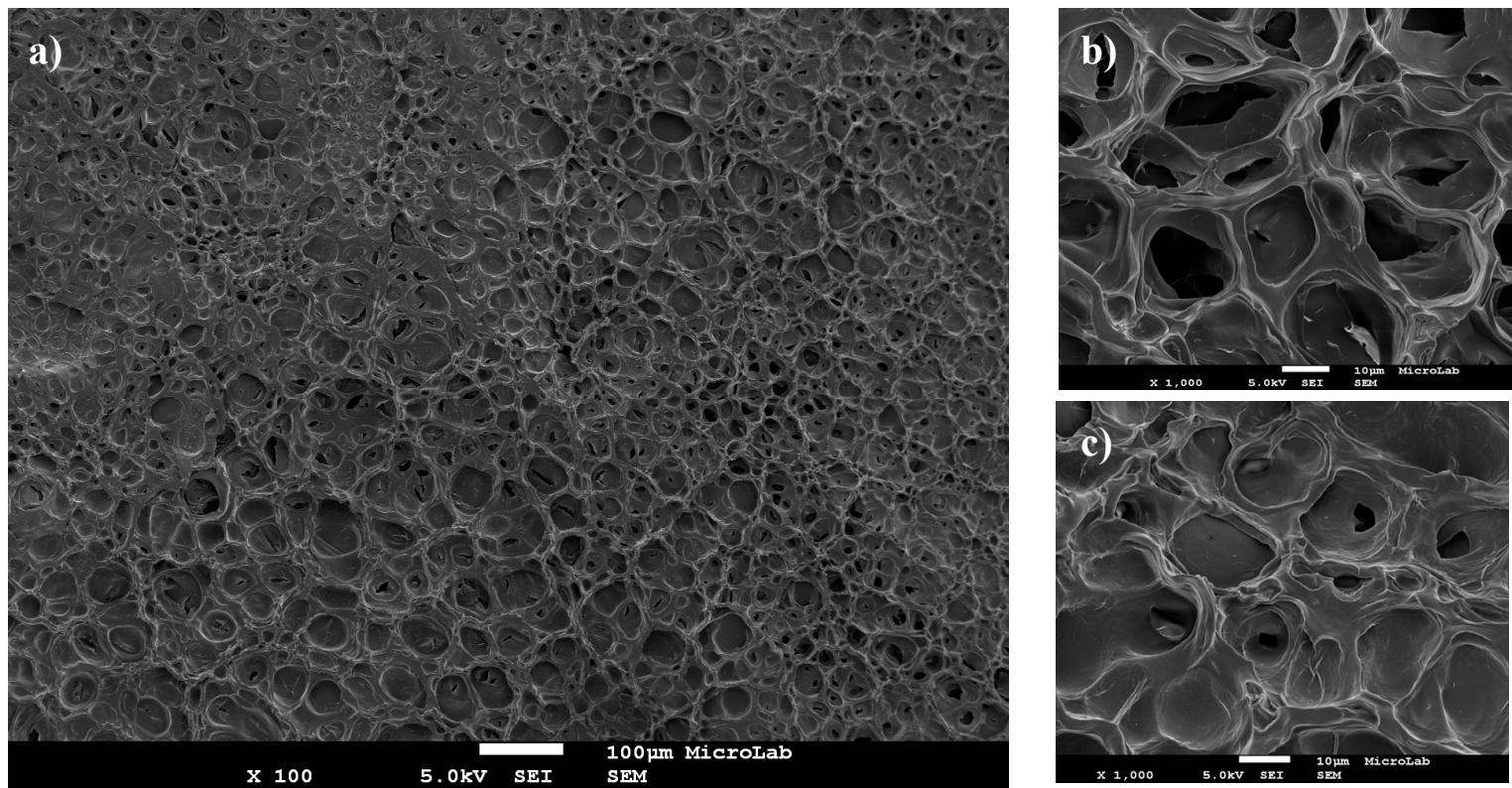

Figure 3. SEM images of lyophilized swollen [emim][EtSO $\left.{ }_{4}\right]$ ION JELLY ${ }^{\circledR}$ films. a) General view; b) and c) Magnified views. 